\title{
Power output fluctuations in large scale PV plants: one year observations with one second resolution and a derived analytic model
}

\author{
Javier Marcos ${ }^{1 *}$, Luis Marroyo ${ }^{1}$, Eduardo Lorenzo ${ }^{2}$, David Alvira ${ }^{3}$ and Eloisa Izco ${ }^{4}$ \\ 1 Dpto. Ingeniería Eléctrica y Electrónica, Universidad Pública de Navarra, Campus Arrosadia, 31006 Pamplona, Spain \\ 2 Instituto de Energía Solar, ETSI Telecomunicación, Ciudad Universitaria, s/n, 28040, Madrid, Spain \\ 3 Red Eléctrica de España, C/Anabel Segura 11, 28108 Alcobendas, Spain \\ 4 Acciona Solar, Avda. de la Ciudad de la Innovación, 3, 31621 Sarriguren, Navarra, Spain
}

\begin{abstract}
The variable nature of the irradiance can produce significant fluctuations in the power generated by large grid-connected photovoltaic (PV) plants. Experimental $1 \mathrm{~s}$ data were collected throughout a year from six PV plants, $18 \mathrm{MWp}$ in total. Then, the dependence of short (below $10 \mathrm{~min}$ ) power fluctuation on PV plant size has been investigated. The analysis focuses on the study of fluctuation frequency as well as the maximum fluctuation value registered. An analytic model able to describe the frequency of a given fluctuation for a certain day is proposed. Copyright (C) 2010 John Wiley \& Sons, Ltd.

KEYWORDS

large PV plants; grid-connected; power fluctuations; analytic model

${ }^{*}$ Correspondence

Javier Marcos, Edificio Los Pinos, Dpto. Ingeniería Eléctrica y Electrónica, Universidad Pública de Navarra, Campus Arrosadia, 31006 Pamplona, Spain.

E-mail: javier.marcos@unavarra.es
\end{abstract}

\section{INTRODUCTION}

The power generated by photovoltaic (PV) plants has a variable character mainly due to the changeability of cloudiness. As penetration of PV energy in the grid increases, such variability can negatively affect power quality and reliability. Nowadays this issue is of special importance in small grids (like islands) with high PV penetration. Thus, the research interest in PV power fluctuations. Irradiance fluctuations have been observed and analysed at Germany [1,4] Japan [2], Belgium [3] and Australia [4] USA [8-13]. However, power output fluctuations analyses are significantly scarce. The available experimental data consist of a 1 year $5 \mathrm{~min}$ data from $100 \mathrm{PV}$ sites (totalling $243 \mathrm{kWp}$ ) in Germany [5]; $10 \mathrm{~s}$ and $1 \mathrm{~min}$ data from a single $4.6 \mathrm{MWp}$ PV site and $10 \mathrm{~min}$ data from three $\sim 100 \mathrm{~kW}$ sites in Arizona (USA) [6] and 3 month 1 min data from 52 PV sites of an average of $3.2 \mathrm{kWp}$, in Japan [7].

In this paper, 1 year $1 \mathrm{~s}$ data from six PV plants in Spain, ranging from 1 to $9.5 \mathrm{MWp}$ totalling $18 \mathrm{MWp}$, has been considered. In addition to this, data from two sections (correspondingly, 48 and $143 \mathrm{kWp}$ ) of a PV plant have also been registered. Particular attention has been paid to the analysis of the influence on the magnitude of the power fluctuations of both, the size of the PV plant and the sampling period. An analytical model to describe the daily frequency of undergoing a power fluctuation of a certain magnitude is presented. Further studies to assess the geographic smoothing are currently undertaken and will be reported in the near future.

\section{EXPERIMENTAL SET-UP}

Figure 1 and Table I detail the location of the six sites considered, and the power and extension of the PV plants. The plants under analysis are scattered over a $\sim 1000 \mathrm{~km}^{2}$ area in the south of Navarra (Spain). The distancing between the plants ranges from 6 to $60 \mathrm{~km}$. All the PV plants are equipped with vertical axis trackers, and feed power to the $13.2 \mathrm{kV}$ grid. Table I also shows the shortcircuit power of the grid at the point of common coupling for each installation. 


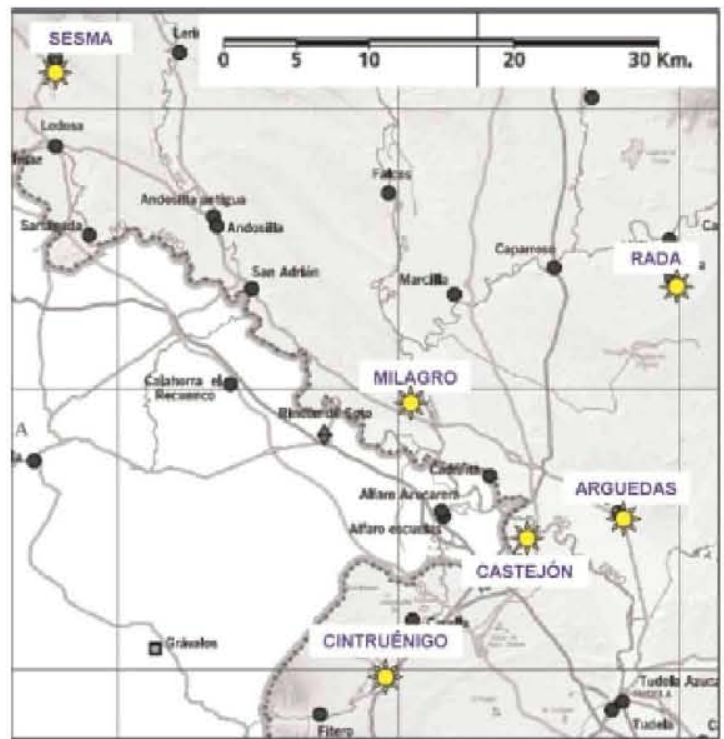

Figure 1. Location of the 6 PV plants under study

Figure 2 shows the experimental set-up installed at the PV plants. Power output $1 \mathrm{~s}$ data are obtained at the point of common coupling by means of a power meter (AllenBradley, Powermonitor), and are recorded by a PLC (AllenBradley, CompactLogix). Simultaneously, the short circuit current of a reference PV module provide a measurement of in-plane irradiance, which is also recorded. Wind speed (at $2 \mathrm{~m}$ high), ambient temperature and cell temperature are registered too. Timing is controlled by means of a GPS so that the records from all the sites can be precisely synchronized. Data recording started on April 17th, 2008 and is still undergoing. Current rough data is over $45 \mathrm{~GB}$.

As an example, Figure 3 shows the irradiance, $G\left(\mathrm{~W} / \mathrm{m}^{2}\right)$ and the output power (normalized and scaled by a factor of $\left.1000, P_{\mathrm{N}}\right)$ recorded at Milagro 9.5 MW site, on August 12th, from 13:07 to 13:20 h. Because of the big size of the PV plant, the power curve is significantly smoother than the irradiance.

\section{DEFINITIONS}

The magnitude of a power fluctuation $\Delta P_{\Delta t}(t)$ at an instant $t$ for a given sampling period, $\Delta t$, is calculated as the difference between the two power outputs, normalized to

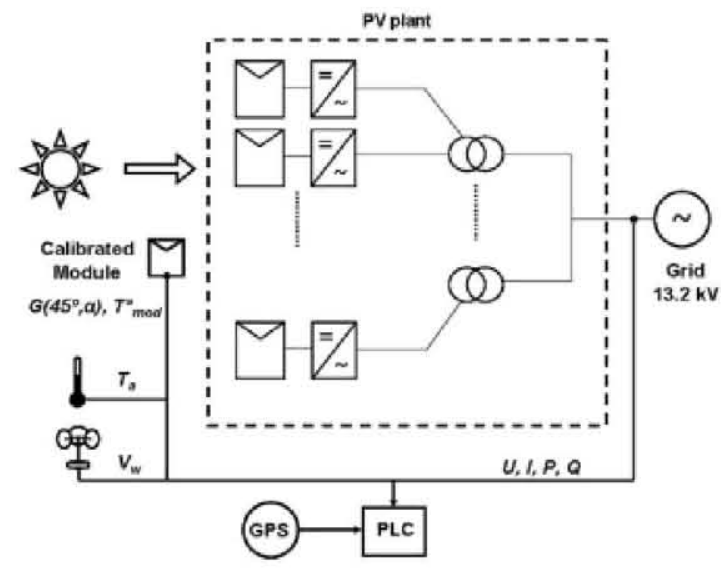

Figure 2. Diagram of the experimental set-up

the transformer power $P^{*}$ of the plant under consideration, Equation (1). That is:

$$
\Delta P_{\Delta t}(t)=\frac{[P(t+\Delta t)-P(t)]}{P^{*}}
$$

This definition can also be applied to irradiance fluctuations, $\Delta G_{\Delta t}$, normalizing by $G^{*}=1000 \mathrm{~W} / \mathrm{m}^{2}$.

Now, let us consider a time series of power outputs. The fluctuations during a certain elapsed time might be observed by going over the series with a $\Delta t$ wide time window. This window has the same time step that the raw data resolution (1s). This way, a time series of power fluctuation is derived from a time series of power output for a given $\Delta t$. Note that $\Delta t$ can be any multiple of the raw data resolution. Figure 4 shows the fluctuation evolution corresponding to the irradiance $(\Delta G)$ and the output power $(\Delta P)$ of Figure 3, for $\Delta t=10$ and $60 \mathrm{~s}$. The smoothing from irradiance to power is clearly observed in both $\Delta t$ cases. As expected, the larger the sampling-time, the larger the fluctuations.

Strictly speaking, the magnitude of a fluctuation $\Delta P_{\Delta t}(t)$ at an instant $t$ for a given $\Delta t$ must be calculated as the difference between the maximum and the minimum values observed all over $\Delta t$, that is:

$$
\Delta P_{\Delta t}(t)=\frac{\max [P(t, t+\Delta t)]-\min [P(t, t+\Delta t)]}{P^{*}}
$$

It can be argued that results given by Equation (1) do not properly represent the real fluctuation because aliasing can occur, particularly for relatively large values of $\Delta t$. However,

\begin{tabular}{|c|c|c|c|c|c|}
\hline PV plants & Peak power (kWp) & Rated power (kW) & Area $(\mathrm{Ha})$ & Grid short-circuit power (MVA) & Location (Lat; Lon) \\
\hline Arguedas & 958 & 775 & 4.1 & 38.8 & $42^{\circ} 10^{\prime} 32^{\prime \prime} \mathrm{N} \mathrm{1} 1^{\circ} 35^{\prime} 28^{\prime \prime} \mathrm{W}$ \\
\hline Sesma & 990 & 800 & 4.2 & 43.4 & $42^{\circ} 27^{\prime} 43^{\prime \prime} N 2^{\circ} 5^{\prime} 31^{\prime \prime} \mathrm{W}$ \\
\hline Cintruénigo & 1438 & 1155 & 6.4 & 41.2 & $42^{\circ} 3^{\prime} 35^{\prime \prime} \mathrm{N} 1^{\circ} 47^{\prime} 50^{\prime \prime} \mathrm{W}$ \\
\hline Rada & 1780 & 1400 & 8.7 & 36.6 & $42^{\circ} 19^{\prime} 3.25^{\prime \prime} \mathrm{N} 1^{\circ} 34^{\prime} 10^{\prime \prime} \mathrm{W}$ \\
\hline Castejón & 2640 & 2000 & 11.8 & 38.9 & $42^{\circ} 9^{\prime} 7^{\prime \prime} \mathrm{N} 1^{\circ} 39^{\prime} 36^{\prime \prime} \mathrm{W}$ \\
\hline Milagro & 9500 & 7243 & 52 & 49.7 & $42^{\circ} 15^{\prime} 28.24^{\prime \prime} \mathrm{N} 1^{\circ} 46^{\prime} 30^{\prime \prime} \mathrm{W}$ \\
\hline Milagro section 1 & 48 & 35 & 0.21 & - & $42^{\circ} 15^{\prime} 28.24^{\prime \prime} \mathrm{N} 1^{\circ} 46^{\prime} 30^{\prime \prime} \mathrm{W}$ \\
\hline Milagro section 2 & 143 & 100 & 0.63 & - & $42^{\circ} 15^{\prime} 28.24^{\prime \prime} \mathrm{N} 1^{\circ} 46^{\prime} 30^{\prime \prime} \mathrm{W}$ \\
\hline
\end{tabular}

Table I. PV plants characteristics 


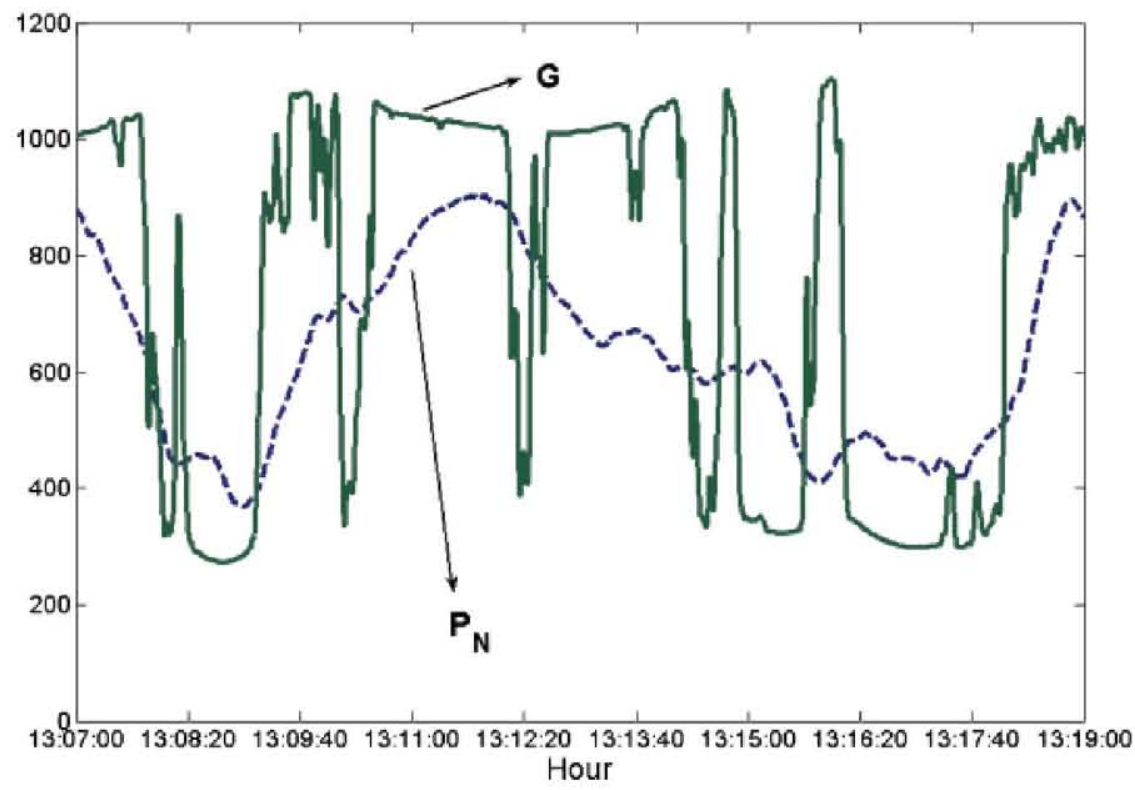

Figure 3. Irradiance, $G\left(\mathrm{~W} / \mathrm{m}^{2}\right)$, and output power $P_{\mathrm{N}}$ (normalized and scaled by a factor of 1000$)$ recorded at Milagro site during a $15-$ $\min$ period on $12 / 8 / 2008$

(a)

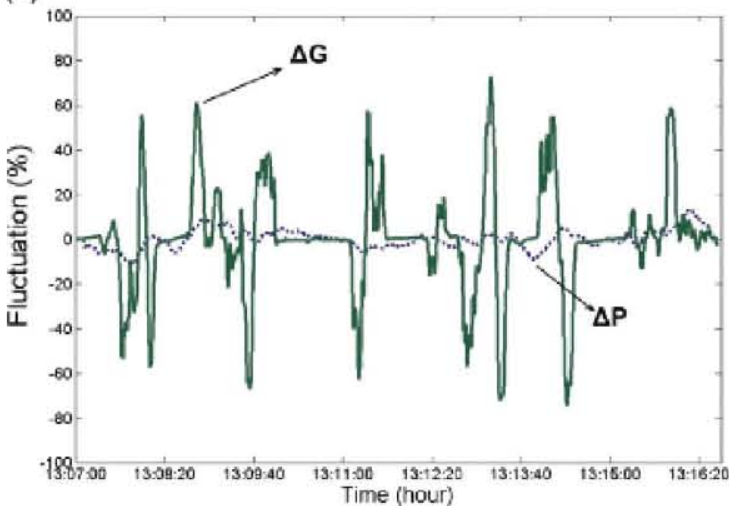

(b)

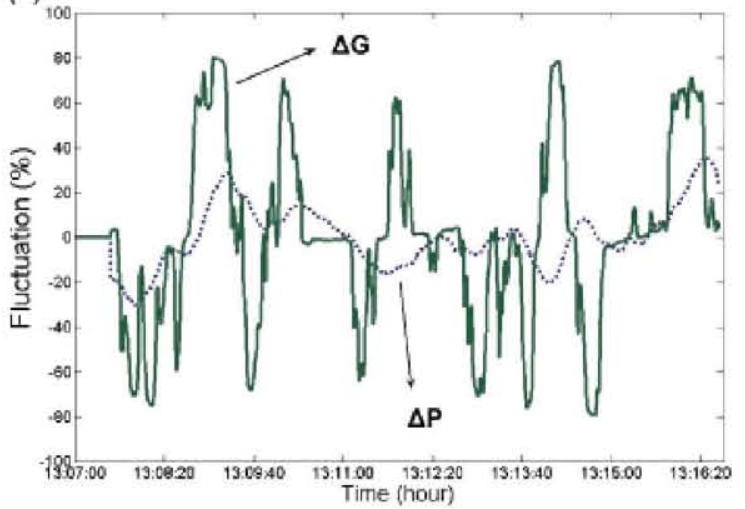

Figure 4. Irradiance fluctuation $\Delta G$ (solid green line) and power fluctuation $\Delta P$ (blue dashed line) evolution recorded at Milagro site during an almost 15 -min period, for (a) $\Delta t=10 \mathrm{~s}$; (b) $\Delta t=60 \mathrm{~s}$

this work is restricted to $\Delta t<600 \mathrm{~s}$, because this period of time represents a borderline in terms of grid operator reaction. Typically, below $600 \mathrm{~s}$ power fluctuations are absorbed by the grid as frequency fluctuations, thus affecting power quality. On the other hand, over $600 \mathrm{~s}$ the network operator can comfortably react by adding (or subtracting) power from other sources. In the range of $\Delta t<600 \mathrm{~s}$ frequency distributions of power fluctuations calculated by Equation (1) are very close to those given by Equation (2). This is clearly observed at Figure 5, which shows the distributions $^{1}$ of the maximum daily power fluctuation

${ }^{1}$ Strictly speaking, a distribution is a curve corresponding to a continuous variable. In practice, fluctuation distributions are obtained as normalized histograms for a large number of fluctuation intervals of very narrow width, $1 \%$. observed during a year (365 values, once per day), for $\Delta t$ equal to 20 and $600 \mathrm{~s}$. Therefore in this paper, the fluctuations have been calculated by Equation (1), in order to open the door to comparison with experiments performed at different sampling periods, like the ones referred above.

\section{IRRADIANCE FLUCTUATIONS}

Figure 6 shows the irradiance fluctuations distributions observed at the Cintruenigo site during a full year (from May 2008 to April 2009) for $\Delta t=10,20,60$, and $600 \mathrm{~s}$. All the distributions are normalized, so that the total area below the curve equals one. Visual appearance gives a different impression because frequency axis has a logarithmic scale. These distributions are clearly symmetric, reflecting the 
(a)

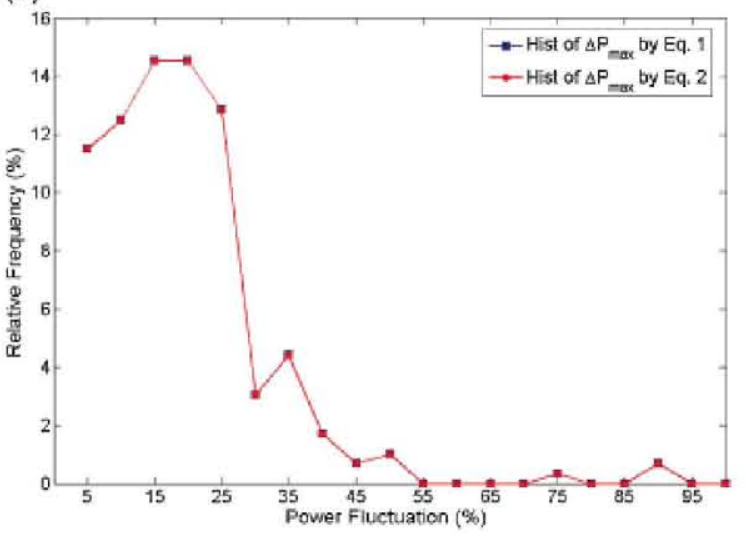

(b)

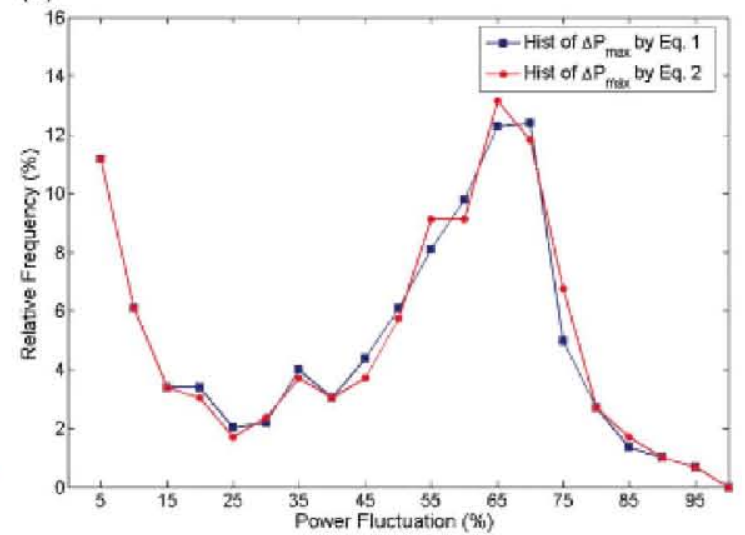

Figure 5. Distributions of the maximum daily power fluctuation, $\Delta P_{\mathrm{MAX}}$, observed during a year, for At equal to $20 \mathrm{~s}$ (a) and $600 \mathrm{~s}$ (b). The power fluctuation has been calculated in two ways, by Equation (1) (red line) and Equation (2) (blue line)

obvious fact that cloud passage entails, both, an irradiance reduction (when clouds arrive) and an irradiance increase (when clouds leave). A positive correlation between the fluctuation magnitude and the sampling time is observed again. Table II gathers the values of some fluctuation intervals. Note that a significant fluctuation let us say larger than $3 \%$ in $1 \mathrm{~s}$, is relatively rare. In fact, this is why frequency is presented in logarithmic scale in Figure 6. However, the relative frequency is near $41 \%$ in $600 \mathrm{~s}$.

Figure 7 shows the largest observed fluctuation versus $\Delta t$ along the year. Values over $80 \%$ are observed for any $\Delta t>2 \mathrm{~s}$. Values over $100 \%$ correspond to irradiances larger than $1000 \mathrm{~W} / \mathrm{m}^{2}$, which are typically associated to reflection effects caused by cloud edges. The 90 th percentile has also been represented. It is about $20 \%$ below the largest fluctuation. It is noteworthy that all the irradiance fluctuation features calculated at the rest of places (and not presented here), essentially coincide with the features at Cintruénigo site, in accordance with the fact that all sites belong to the same climatic region. This way, the same mathematical description of the phenomenon applies for all the sites. In other words, the power fluctuations are not influenced by geographic aspects. Moreover, it has been checked that the monthly fluctuation distributions are very similar between them and also comparable to yearly distributions. In consequence, this represents an argument in favour of considering the fluctuations as a stationary statistic process. In other words, the distributions presented here can also be viewed as probability density functions, in yearly or monthly terms. However, stationarity is far from being preserved in daily terms. In fact, some days do exhibit frequent fluctuations while other days practically do not.

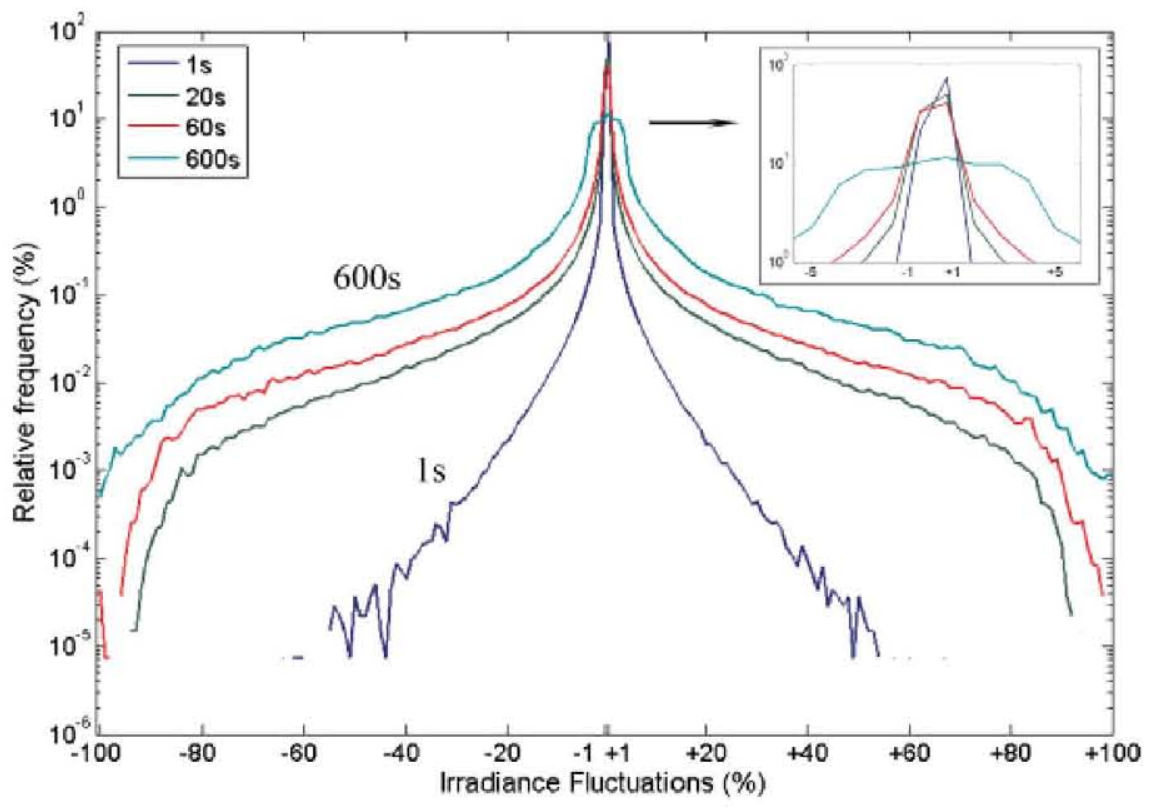

Figure 6. Distributions of the irradiance fluctuations, $\Delta G$, registered at Cintruenigo site during a full year, for $\Delta t=1,20,60$ and $600 \mathrm{~s}$ 
Table II. Influence of $\Delta t$ on the frequency distributions of the fluctuations

\begin{tabular}{lcrr}
\hline$\Delta G(\%)$ & \multicolumn{3}{c}{$\Delta t(s)$} \\
\cline { 2 - 4 } & $1 \mathrm{~s}$ & $20 \mathrm{~s}$ & $60 \mathrm{~s}$ \\
\hline $0 \% \leq \Delta G \leq 3 \%$ & $98.94 \%$ & $92.51 \%$ & $600 \mathrm{~s}$ \\
$3 \% \leq \Delta G \leq 10 \%$ & $0.92 \%$ & $4.47 \%$ & $87.50 \%$ \\
$10 \% \leq \Delta G \leq 50 \%$ & $0.16 \%$ & $2.71 \%$ & $7.61 \%$ \\
$50 \% \leq \Delta G \leq 100 \%$ & $2.35 \times 10^{-4} \%$ & $0.32 \%$ & $4.66 \%$ \\
\hline
\end{tabular}

Grid operators require power fluctuation forecasts with similar anticipation weather forecasts; let us say in daily terms. Looking for that, we have analysed the fluctuations in these terms. Considering as relevant fluctuations those which absolute value is over a certain threshold, i.e. $\operatorname{abs}\left(\Delta G_{\Delta t}\right)>u$, the total length of the day from sunrise to sunset, $T_{\mathrm{D}}$, can be divided in two parts, $T_{\Delta G>u}$ and $T_{\Delta G \leq u}$, depending on the occurrence or not of such relevant fluctuations. As an example, Table III gives some values for $u=3 \%$ and $\Delta t=20$ and $600 \mathrm{~s}$, for 4 days. Figure 8 shows the frequency distribution of only relevant fluctuations for April 29th. These distribution functions can be adjusted to an exponential function:

$$
\left.f(x)\right|_{\Delta G>u}=a e^{-b x}
$$

Obviously, the curve enclosed area must equal one. Hence, assuming $u<<100$ and considering that fluctu-

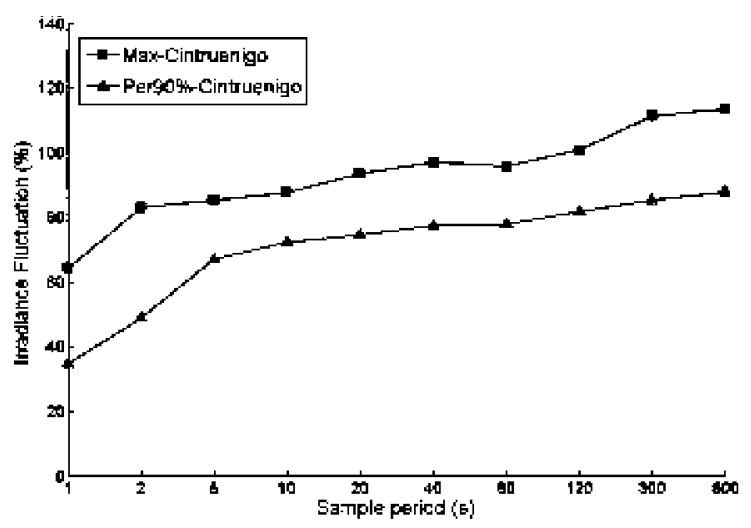

Figure 7. Maximum irradiance fluctuation $\Delta G$ and 90 th percentile registered at Cintruenigo site ations larger than $100 \%$ are so scarce that can be neglected:

$$
\begin{aligned}
& \left.\int_{u}^{100} f(x)\right|_{\Delta G>u} \mathrm{~d} x=\frac{a}{b}\left(e^{-b u}-e^{-b 100}\right) \approx \frac{a}{b} e^{-b u}=1 \\
& \Rightarrow a=b e^{b u}
\end{aligned}
$$

which leads to

$$
\left.f(x)\right|_{\Delta G>u}=b e^{-b(x-u)}
$$

Table III also presents $b$ values calculated for the cases considered above. The corresponding regression coefficients, $R^{2}$, are close to one. It should be stressed that $T_{\Delta G>u} l$ $T_{\mathrm{D}}$ and $b$ values are specific for each $\Delta t$ and for each day, so they must be obtained from the analysis of the fluctuations observed on each particular day. Obviously, fluctuation

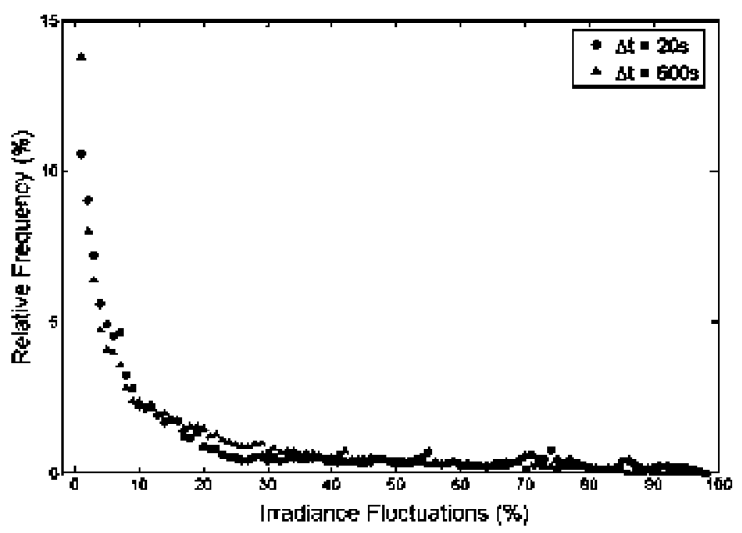

Figure 8. Frequency distribution of the irradiance fluctuations,

Table III. Distribution function parameters

\begin{tabular}{lccccccc}
\hline Date & $K t$ & $\Delta t(\mathrm{~s})$ & $T_{\Delta G>} J T_{\mathrm{D}}$ & $b$ & $R^{2}$ & $\Delta G_{\max }(\%)$ & $F(x>40 \%)(\%)$ \\
\hline 1/May/2008 & 0.70 & $20 \mathrm{~s}$ & 0.02 & 0.18 & 0.94 & 2 & 0.002 \\
& & $600 \mathrm{~s}$ & 0.27 & 0.68 & 0.90 & 25 & 0.007 \\
8/Aug/2008 & 0.53 & $20 \mathrm{~s}$ & 0.2 & 0.13 & 0.92 & 40 & 0.16 \\
& & $600 \mathrm{~s}$ & 0.67 & 0.09 & 0.89 & 82 & 2.35 \\
2/Mar/2009 & 0.22 & $20 \mathrm{~s}$ & 0.003 & 0.36 & 0.98 & 9 & 0.0 \\
& & $600 \mathrm{~s}$ & 0.36 & 0.21 & 0.97 & 30 & 0.01 \\
29/Apr/2009 & 0.50 & $20 \mathrm{~s}$ & 0.18 & 0.14 & 0.90 & 53 & 0.006 \\
& & $600 \mathrm{~s}$ & 0.70 & 0.09 & 0.92 & 97 & 0.02 \\
\hline
\end{tabular}



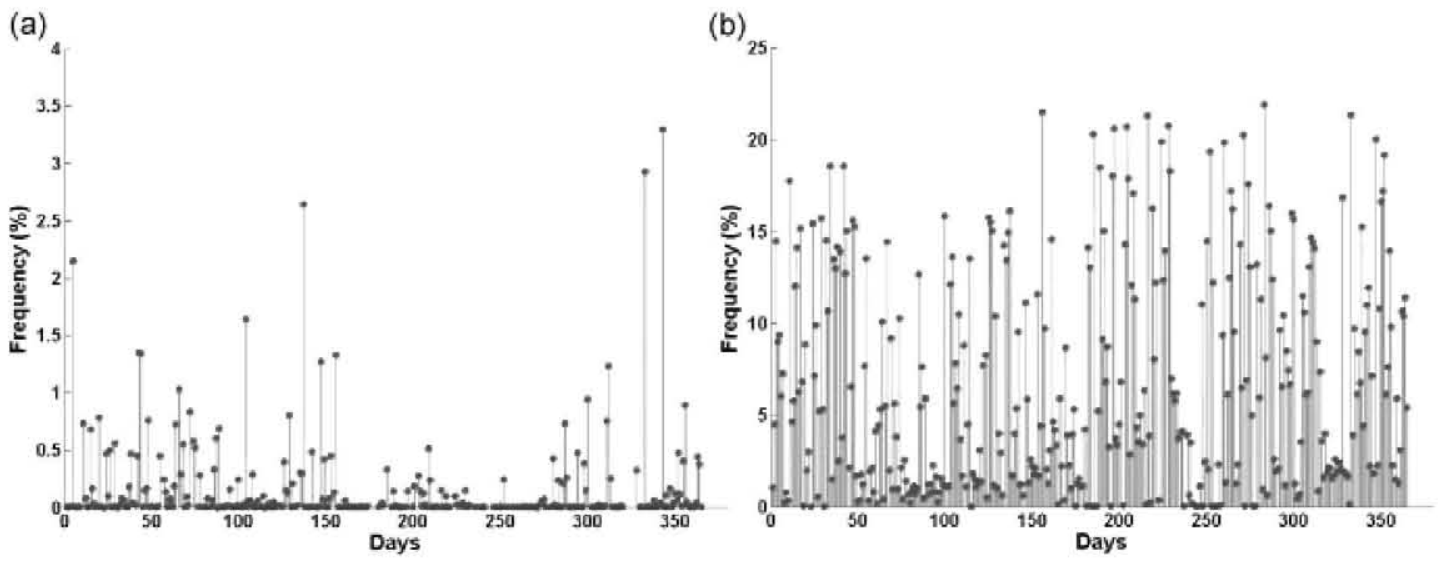

Figure 9. Evolution of the daily frequency of a irradiance fluctuation larger than $40 \%$ in Cintruenigo during a year (a) $\Delta t=20 \mathrm{~s}$; (b) $\Delta t=600 \mathrm{~s}$

occurrence increases when $T_{\Delta G>u} / T_{\mathrm{D}}$ increases, and also when $b$ decreases. The main benefit of this model is that it allows long data sequences (for example containing around 2520 numbers for $\Delta t=20 \mathrm{~s}$ ) to be condensed into just two parameters, without any important loss of information. Moreover, the analytic character of the model allows easy calculations. For example, cumulative frequencies for any given fluctuation interval can easily be calculated now. Once a relevant fluctuation $x$ happens, the cumulative frequency of being larger than $y$, is given by:

$$
\left.F(x>y)\right|_{\Delta G>u}=\int_{y}^{100} f(x) \mathrm{d} x=e^{-b(y-u)}
$$

The frequency distribution Equation (7) and the absolute cumulative frequency Equation (8) are calculated multiplying this function by the frequency of having a relevant fluctuation. That is:

$$
\begin{aligned}
& f(x)=\left\{\begin{array}{l}
x<u ; \&\left(1-\frac{T_{\Delta G>u}}{T_{\mathrm{D}}}\right) \frac{1}{u} \\
x>u ; \& \frac{T_{\Delta G>u}}{T_{\mathrm{D}}} b e^{-(x-u)}
\end{array}\right. \\
& F(x>y)=\left.\frac{T_{\Delta G>u}}{T_{D}} F(x>y)\right|_{\Delta G>u}
\end{aligned}
$$

Figure 9 presents the yearly evolution of this cumulative frequency for fluctuations larger than $40 \%$ for $\Delta t=20$ and $600 \mathrm{~s}$ at Cintruénigo. It has been obtained by previous

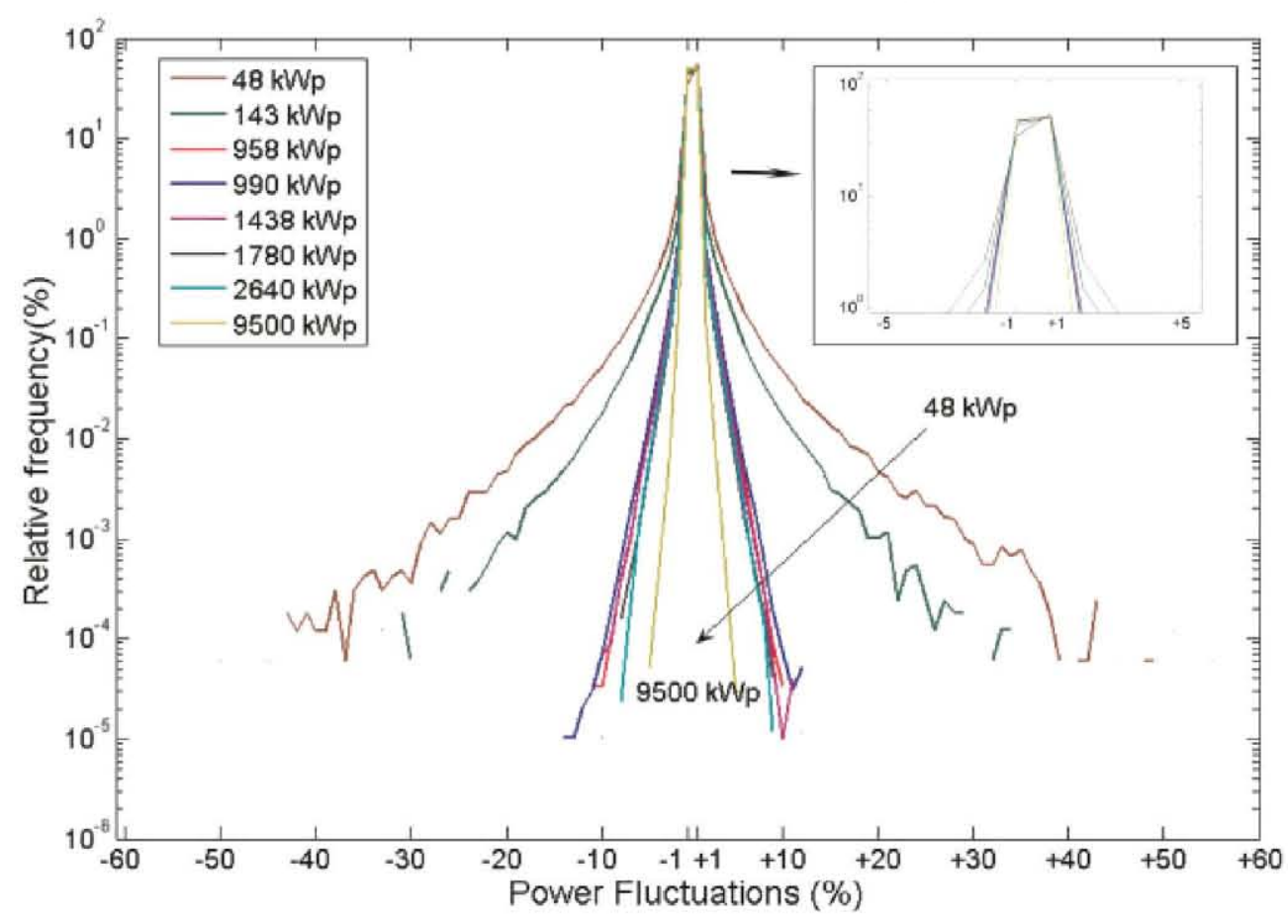

Figure 10. Distribution of the power fluctuations, $\Delta P$, registered during a year at each PV plant for $\Delta t=1 \mathrm{~s}$ 


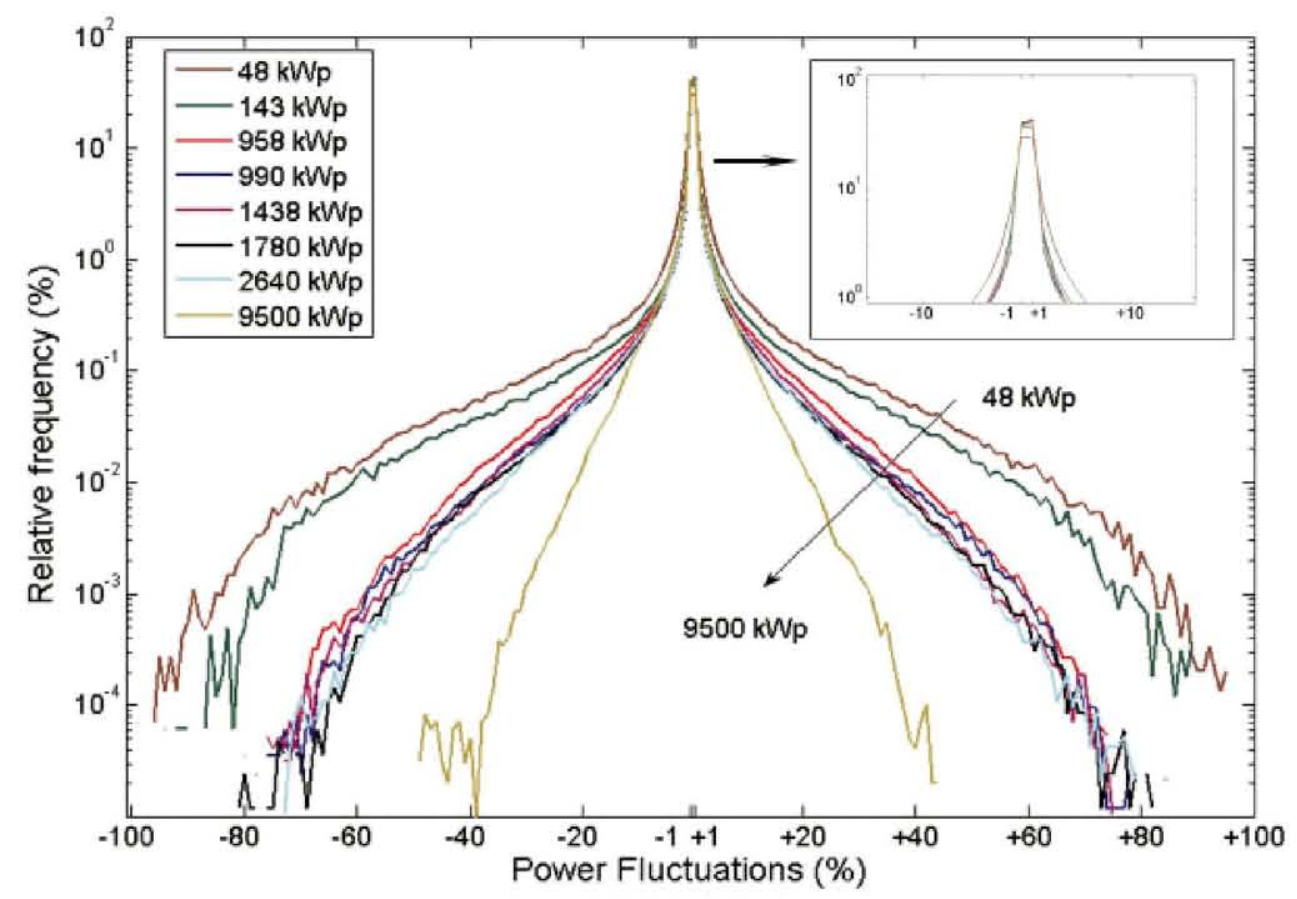

Figure 11. Distribution of the power fluctuations, $\Delta P$, registered during a year at each $\mathrm{PV}$ plant for $\Delta t=20 \mathrm{~s}$

calculation of a pair of $\left(T_{\Delta G>u} / T_{\mathrm{D}}\right)$ and $b$ values for each day of the year. Interestingly enough, the occurrence of this fluctuation is concentrated in only a few days for small $\Delta t$. For example, for $\Delta t=20 \mathrm{~s}$ there are only 11 days where $F(x>40 \%)$ is above $1 \%$. On the other hand, for $\Delta t=600 \mathrm{~s}$, the number of days where $F(x>40 \%)$ is over $10 \%$ is 103 .
Currently ongoing and still provisional studies suggest that risky days result from the combination of high wind speed (about $60 \mathrm{~km} / \mathrm{h}$, or more) with intermediate daily clearness index $\left(0.35<k_{\mathrm{t}}<0.65\right)$. Because wind speed and clearness index can be predicted from 1 day to another (in fact, it is already being done in standard weather forecast), this

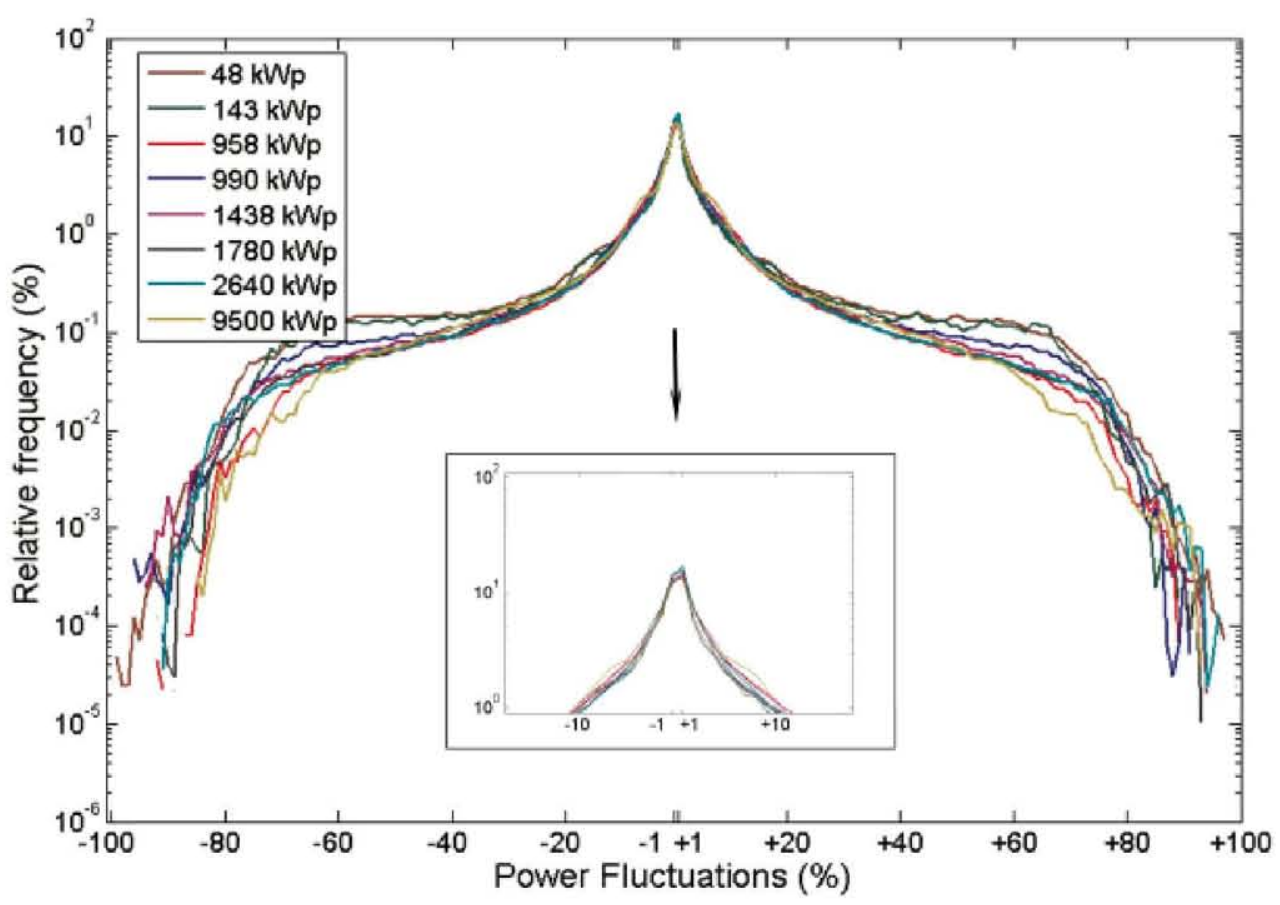

Figure 12. Distribution of the power fluctuations, $\Delta P$, registered during a year at each PV plant for $\Delta t=600 \mathrm{~s}$ 
(a)

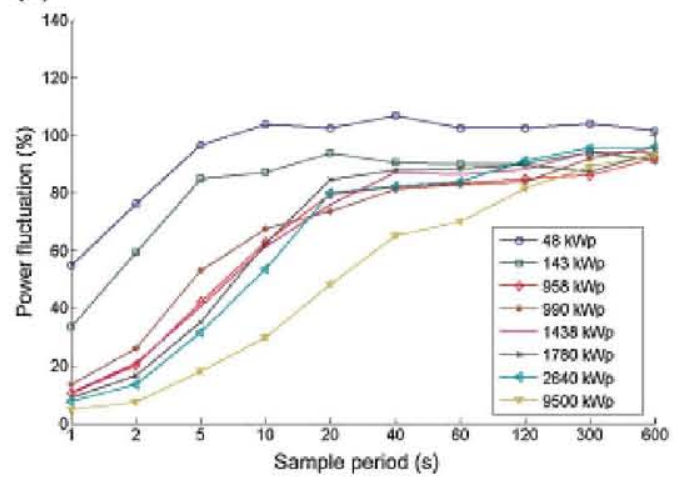

(b)

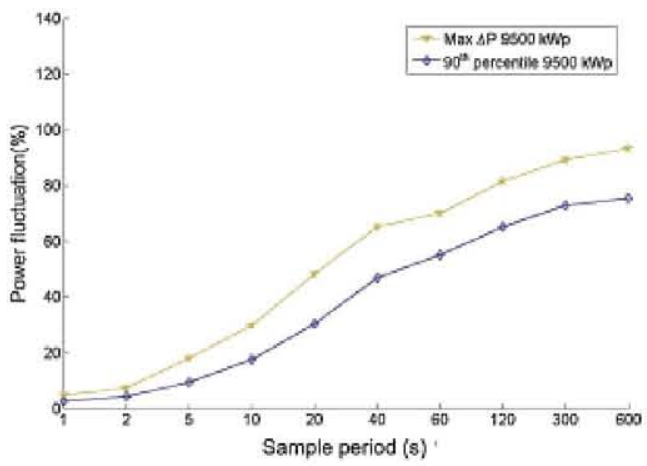

Figure 13. (a) Maximum power fluctuations, $\Delta P$, registered during a year at each $\mathrm{PV}$ plant, (b) maximum power fluctuation, $\Delta P$, and 90th percentile registered at Milagro site $(9500 \mathrm{kWp})$ during a year

likely opens the door for future prediction of fluctuations in daily terms.

Finally, it must be mentioned that all the aforementioned irradiance fluctuation features at the Cintruénigo site described along this paper essentially coincide with all the other sites registered features, in coherence with the fact that all sites belong to the same climatic region.

\section{POWER FLUCTUATIONS}

Besides the intermittence of cloudiness, power output fluctuations are influenced by the size of the PV plant. A priori, the larger the PV plant is, the lower the power output fluctuation should be. In other words, it is anticipated that the PV plant size will smooth power output fluctuations. It is also straightforward to understand that the shorter the sampling time is, the more significant the smoothing effect should be. Figures 10,11 and 12 show the power output fluctuation distributions observed along a full year (from May 2008 to April 2009) in all the here concerned PV plants, for $\Delta t=1,20$ and $600 \mathrm{~s}$. As expected, the smoothing effect is more noticeable with size and is reduced with $\Delta t$.

Figure 13(a) shows for the full year, the largest fluctuation observed in the different PV plants versus $\Delta t$. Figure 13(b) shows the largest fluctuation and also the

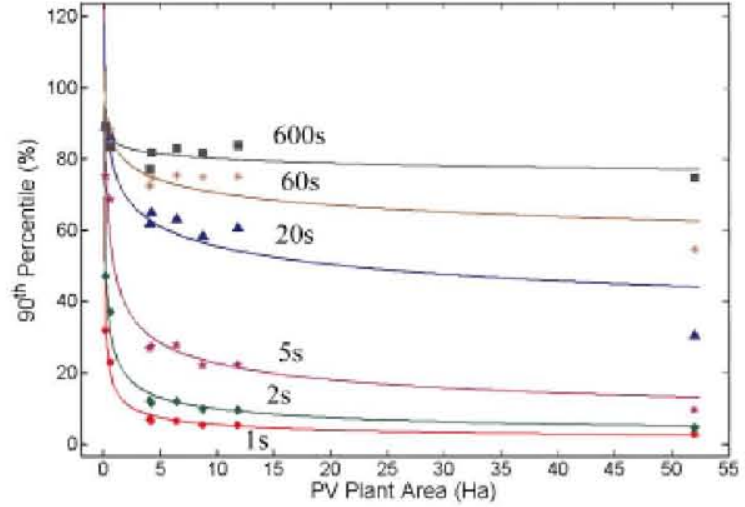

Figure 14. 90th percentile of the registered power fluctuations as a function of the PV plant area

90th percentile observed at Milagro (9.5 MWp) site. Once again, the smoothing effect increases with size and is reduced with $\Delta t$.

Figure 14 shows the 90 th percentile versus the PV plant size, with $\Delta t$ as parameter. Table IV compiles the corresponding values. It is worth mentioning that they can be fitted to an exponential function, such as:

$$
y=m x^{n}
$$

Table IV. 90th percentile of the registered power fluctuations for each PV plant under study

\begin{tabular}{lcccccccc}
\hline PV plant & Peak power (kWp) & Area $(\mathrm{Ha})$ & \multicolumn{5}{c}{ 90th percentile (\%) } \\
\cline { 5 - 9 } & & & $1 \mathrm{~s}$ & $2 \mathrm{~s}$ & $5 \mathrm{~s}$ & $20 \mathrm{~s}$ & $60 \mathrm{~s}$ & $600 \mathrm{~s}$ \\
\hline Milagro section 1 & 48 & 0.21 & 32 & 47 & 75 & 89 & 90 & 89 \\
Milagro section 2 & 143 & 0.63 & 23 & 37 & 69 & 86 & 88 & 84 \\
Arguedas & 958 & 4.1 & 7 & 12 & 28 & 64 & 75 & 84 \\
Sesma & 990 & 4.2 & 6 & 12 & 27 & 63 & 75 & 83 \\
Cintruénigo & 1438 & 6.4 & 6 & 11 & 27 & 61 & 75 & 83 \\
Rada & 1780 & 8.7 & 5 & 11 & 23 & 60 & 74 & 81 \\
Castejón & 2640 & 11.8 & 5 & 10 & 22 & 58 & 72 & 81 \\
Milagro & 9500 & 52 & 3 & 4 & 10 & 30 & 54 & 74 \\
\hline
\end{tabular}


Table V. Estimated $m$ and $n$ parameters

\begin{tabular}{llll}
\hline$\Delta t$ & $m$ & $n$ & $R^{2}$ \\
\hline $1 \mathrm{~s}$ & 15.78 & -0.49 & 0.98 \\
$2 \mathrm{~s}$ & 25.71 & -0.43 & 0.96 \\
$5 \mathrm{~s}$ & 48.40 & -0.33 & 0.93 \\
$20 \mathrm{~s}$ & 76.38 & -0.2 & 0.88 \\
$60 \mathrm{~s}$ & 83.86 & -0.08 & 0.82 \\
$600 \mathrm{~s}$ & 85.20 & -0.02 & 0.75 \\
\hline
\end{tabular}

Table VI. Distribution function parameters for April 29th at Milagro (9.5 MWp) and Sesma (0.990 MWp) PV plants

\begin{tabular}{|c|c|c|c|c|}
\hline \multirow{2}{*}{$\frac{\text { PV plant }}{\Delta t(s)}$} & \multicolumn{2}{|c|}{ Milagro (9.5 MWp) } & \multicolumn{2}{|c|}{ Sesma (0.990 MWp) } \\
\hline & $20 \mathrm{~s}$ & $600 \mathrm{~s}$ & $20 \mathrm{~s}$ & $600 \mathrm{~s}$ \\
\hline$T_{\Delta P>d} d T_{D}$ & 0.14 & 0.68 & 0.19 & 0.63 \\
\hline$b$ & 0.28 & 0.09 & 0.13 & 0.08 \\
\hline$R^{2}$ & 0.98 & 0.93 & 0.97 & 0.93 \\
\hline
\end{tabular}

Table VII. Number of days during a year where cumulative frequency for power fluctuations larger than $40 \%, F(x>40 \%)$, is over 1 and $10 \%$. Fluctuations have been calculated for $\Delta t=20,600 \mathrm{~s}$ and for Milagro (9.5 MWp) and Sesma (0.990 MWp) PV plants.

\begin{tabular}{|c|c|c|c|c|c|c|c|c|}
\hline \multirow{3}{*}{$\begin{array}{l}\text { PV plant } \\
\Delta t(s) \\
F(x>40 \%)\end{array}$} & \multicolumn{4}{|c|}{ Milagro (9.5 MWp) } & \multicolumn{4}{|c|}{ Sesma (0.990 MWp) } \\
\hline & \multicolumn{2}{|c|}{$20 \mathrm{~s}$} & \multicolumn{2}{|c|}{$600 \mathrm{~s}$} & \multicolumn{2}{|c|}{$20 \mathrm{~s}$} & \multicolumn{2}{|c|}{$600 \mathrm{~s}$} \\
\hline & $>1 \%$ & $>10 \%$ & $>1 \%$ & $>10 \%$ & $>1 \%$ & $>10 \%$ & $>1 \%$ & $>10 \%$ \\
\hline No. days & 0 & 0 & 128 & 10 & 13 & 0 & 130 & 8 \\
\hline
\end{tabular}

Table $\mathrm{V}$ presents the $m$ and $n$ values versus $\Delta t$. It is interesting to note that for $\Delta t=1$ and $2 \mathrm{~s}$, the $n$ value is basically -0.5 . Therefore, the smoothing effect for small $\Delta t$ is accurately described by a $1 / \sqrt{S}$ law, where $S$ is the PV plant extension. This can be explained taking into consideration that shades typically move in one dimension while power is essentially related to surface or two dimensions. However, for the PV plant areas considered in this paper and for long $\Delta t(>20 \mathrm{~s})$, the power fluctuations are not influenced by the size of the plant, due to the shadows have enough time to completely cover the plant.

The frequency distribution Equation (10) and the absolute cumulative frequency Equation (11) of relevant power fluctuations $\left(\operatorname{abs}\left(\Delta P_{\Delta t}\right)>\mathrm{u}\right)$ for a given day can be described similarly to the irradiance:

$$
f(x)=\left\{\begin{array}{l}
x<u ; \&\left(1-\frac{T_{\Delta P>u}}{T_{\mathrm{D}}}\right) \frac{1}{u} \\
x>u ; \& \frac{T_{\Delta P_{\supset} u}}{T_{\mathrm{D}}} b e^{-(x-u)}
\end{array}\right.
$$

and

$$
F(x>y)=\left.\frac{T_{\Delta P>u}}{T_{\mathrm{D}}} F(x>y)\right|_{\Delta P>u}=\frac{T_{\Delta P>u}}{T_{\mathrm{D}}} e^{-b(y-u)}
$$

Now, the values of $\left(T_{\Delta P>u} / T_{\mathrm{D}}\right)$ and $b$ for each day depend on $\Delta t$ and also on the PV plant size. Table VI presents some values for April 29th, $\mathrm{u}=3 \%, \Delta t=20$ and $600 \mathrm{~s}$, and for two different sites: Sesma $(0.990 \mathrm{MWp})$ and
Milagro (9.5 MWp). Table VII shows the number of days during a year where cumulative frequency for fluctuations larger than $40 \%, F(x>40 \%)$ is over 1 and $10 \%$, for $\Delta t=20,600 \mathrm{~s}$ and for Sesma and Milagro PV plants. The smoothing effect becomes evident in the lower frequencies of the biggest PV plant, but only for $\Delta t=20 \mathrm{~s}$. Likewise, the occurrence of relevant fluctuations is concentrated on only a few days. Current studies are focused on the prediction of those problematic days through standard weather data. This will be critical to establish a relationship between parameter $b$ and $T_{\Delta P>u} / T_{\mathrm{D}}$ values depending on the PV plant size and the meteorological conditions of a particular day.

\section{CONCLUSIONS AND OUTLOOK}

Power supply quality and network security could be seriously affected by PV plants power fluctuations in a near future, due to irradiance variability. This work is based on 1 year data with a $1 \mathrm{~s}$ resolution from six different PV plants (adding up to $18 \mathrm{MWp}$ ). The analysis of the data has revealed the smoothing effect of PV plant size on power fluctuations. Moreover, such smoothing effect has been found strongly dependent on the sampling-time considered. An empirical expression has been proposed in order to calculate the fluctuation magnitude for short time periods. 
The statistical study of the daily power fluctuations has allowed the analytic description of the fluctuation frequency, as well. Furthermore, current research efforts deal with the smoothing effect associated to the combination of the six PV plants and the forecast of the most risky days. Methods for daily prediction of wind speed and clearness index are well developed. In fact, this is routinely done in weather forecast. Hence, if it is finally confirmed, the relation between these meteorological parameters and power fluctuations will permit the prediction of the last ones. It is worth to note that the probability of a certain maximum power fluctuation is the key for establishing the maximum allowed PV penetration rate at a particular grid.

\section{ACKNOWLEDGEMENTS}

The authors would like to thank Red Eléctrica de España (REE) for their financial support and ACCIONA for authorizing measurements at its PV plants and for their staff helpful collaboration. Likewise, Pedro Zufiria has provided invaluable technical support on the analytic description of the fluctuation frequency. Finally, two anonymous reviewers have provided extremely clever comments to the first version of the paper. This work has been also supported by the Spanish Ministry of Education and Science (grant number: DPI2009-14713-C03-01).

\section{REFERENCES}

1. Beyer HG, Decker B, Luther J, Steinberg-Willms R. "Spatial and temporal characteristics of short term fluctuations in solar radiation for PV-plant applications', 10th European Photovoltaic Solar Energy Conference, 8-12 April, 1991 Lisbon, Portugal, 453 456.

2. Otani K, Minowa J, Kurokawa K. Study on areal solar irradiance for analyzing areally-totalized PV systems. Solar Energy Materials and Solar Cells 1997; 47: 281-288.

3. Woyte A, Thong VV, Belmans R, Nijs J. Voltage fluctuations on distribution level introduced by photo- voltaic systems. IEEE Transactions on Energy Conversion 2006; 21: 202-209.

4. Woyte A, Belmans R, Nijs J. Fluctuations in instantaneous clearness index: analysis and Statistics. Solar Energy 2007; 81: 195-206.

5. Wiemken E, Beyer HG, Heydenreich W, Kiefer K. Power characteristics of PV ensembles: experiences from the combined power production of 100 Grid connected PV systems distributed over the area of Germany. Solar Energy 2001; 70(6): 513-518.

6. Curtright E, Apt J. The character of power output from utility-scale photovoltaic systems. Progress in Photovoltaic: Research and Applications 2008; 16: 241247.

7. Murata A, Yamaguchi H, Otani K. A method of estimating the output fluctuation of many photovoltaic power generation systems dispersed in a wide area. Electrical Engineering in Japan 2009; 166(4): 645652.

8. Jewell WT, Ramakumar R. The effects of moving clouds on electric utilities with dispersed photovoltaic generation, Paper no 887 WM 229-8, presented at the IEEE Power Engineering Society1987 Winter Meeting, New Orleans, 1-6 February 1987.

9. Jewell WT, Ramakumar R, Hill SR. A Study of Dispersed Photovoltaic Generation on the PSO System. IEEE Transactions on Energy Conversion 1988; 3(3).

10. Jewell WT, Unruh TD. Limits on cloud-induced fluctuation in photovoltaic generation. IEEE Transactions on Energy Conversion 1990; 5(1): 8-14.

11. Chowdhury BH, Rahman S. Is central station photovoltaic power dispatchable? IEEE Transactions on Energy Conversion 1988; 3(4): 747-754.

12. Chowdhury BH. Effect of central station photovoltaic plants on power system security, Proceedings of 21st IEEE Photovoltaic Specialist Conference, Kissimmee, FL, May 1990.

13. Chowdhury BH. Optimizing the integration of photovoltaic systems with electric utilities. IEEE Transactions on Energy Conversion 1992; 7(1): 72-78. 